\title{
Enhancing Learning Through Different Cues in Multimedia Materials
}

\author{
Renante Egcas \\ Northern Negros State College of Science and Technology, Sagay City, Philippines
}

\begin{abstract}
This study sought to determine the effects of multimedia language instruction with varying number of visual and verbal cues on the vocabulary achievement of education students. Multimedia materials differ in the number and quality of visual and verbal cues. Many of these cues, such as facial expressions, gestures, proximity, appearance, and tone of voice, have been found to be beneficial to the learning process. This is an experimental research which used the randomized multi-group with a pre-test and post-test design. There were 60 research respondents involved in this study. They were randomly assigned to four treatment groups (TGs) employing the randomized matching technique on the basis of mental ability and vocabulary ability. Each TG received six multimedia lessons on vocabulary set in four experimental variables, such as $\mathrm{TG}_{1}$ — video: full visual and verbal cues; $\mathrm{TG}_{2}$ — still picture, text, and audio: limited visual and full verbal cues; $\mathrm{TG}_{3}$ — still picture and text: limited visual and no verbal cues; and $\mathrm{TG}_{4}$ - audio only: no visual and full verbal cues. The vocabulary achievement of the research participants was correlated to gender, age, socio-economic status (SES), grade point average (GPA) in English, and attitudes towards multimedia instruction. Statistical analyses showed no significant difference in the vocabulary achievement among the four TGs. Significant relationships were noted only between age and vocabulary achievement and between GPA in English and vocabulary achievement.
\end{abstract}

Keywords: multimedia, cues, vocabulary, achievement

\section{Introduction}

Technology management in education should focus on educational technology or instructional technology — a systematic, iterative process for designing instruction or training used to improve performance. It should encourage wise use of systems, environments, tools, products, and strategies that can enhance human learning and competence. As such, it stresses a rigorous analysis of present and desired levels of performance, identifies the causes for any performance gaps, offers a wide range of solutions with which to improve performance, guides the change management process, and evaluates the results (Walden, 2005).

To keep education attuned to technological advancement, technology managers in education sector should also "respond effectively to rapid technological changes and innovations by harnessing these to enhance the productivity, quality, competitiveness, and service of their respective organizations" (Technology Management Center/University of the Philippines, 2008).

Jenny Davidson, in her article "Multimedia Presentation", stressed that students and teachers are

Renante Egcas, Ph.D., professor IV and vice president for academic affairs, Northern Negros State College of Science and Technology. 
increasingly helped by multimedia presentations that are both helpful and fun, however ... it will not do much if it is part of poorly designed or badly chosen materials (Davidson, n.d.). It is in this aspect that help and/or intervention of the technology managers are needed.

The global range of development related to multimedia in the classroom is enormous. However, the rapid growth of multimedia implementation in learning settings does not guarantee participation and acceptance on the part of students. Negative attitudes towards multimedia-based instruction could be a deterrent to using multimedia technology as a tool for language learning (Houghton, 2004).

With its goal to maximize the utilization of multimedia instruction both in professional subjects and general education subjects, Northern Negros State College of Science and Technology (NONESCOST), through this study, established empirical evidence especially on the use of multimedia presentations in the classroom. The teachers in this school are mostly using multimedia materials in the classroom, yet the designs of presentations are "usually based on intuition rather than on empirical evidence, and little is known about their actual effect to the end users - the learners" (Betrancourt, 2007). Hence, sometimes, cues are overloaded if not indiscriminatingly eliminated.

Furthermore, this study is deemed vital in the sense that NONESCOST caters to more than $70 \%$ of students from public high schools, in which computer and/or media literacy programs are quite limited, thus, their acceptance and readiness to this teaching-learning environment, especially in a language classroom, may be a factor to learning because the under-supported digital technology systems and digital curriculum of public schools lead to a growing "digital divide" within public school education ... and that of higher education in the Philippines.

\section{Research Objectives}

This study aimed to determine the effects of multimedia language instruction with varying visual and verbal cues on the vocabulary achievement of education students at NONESCOST as basis for an enriched instructional design.

Specifically, this study sought answers to the following three questions:

1. What is the vocabulary achievement of each treatment group (TG) before and after exposure to multimedia language instruction with: (a) $\mathrm{TG}_{1}$ (full visual and verbal cues); (b) $\mathrm{TG}_{2}$ (limited visual and full verbal cues); (c) $\mathrm{TG}_{3}$ (limited visual and no verbal cues); and (d) $\mathrm{TG}_{4}$ (no visual and full verbal cues).

2. Is there a significant difference among the four TGs in their vocabulary achievement?

3. Is there a significant relationship between the respondents' vocabulary achievement and identified profile variables?

\section{Theoretical Framework}

This study was anchored primarily on the Mayer's cognitive theory of multimedia learning (CTML) which centers on the idea that learners attempt to build meaningful connections between words and pictures and that they learn more deeply than they could have with words or pictures alone (Mayer, 2010).

According to CTML, one of the principal aims of multimedia instruction is to encourage the learner to build a coherent mental representation from the presented material. The learner's job is to make sense of the presented material as an active participant, ultimately constructing new knowledge.

Similarly, this study was also based on the premise that humans can integrate information from different 
sensory modalities (visual, auditory, and kinesthetic) into one meaningful experience (learning) and/or from verbal and non-verbal information into a mental model (schema). In this context, instructional designers and teachers are confronted with the need to choose between several combinations of modes and modalities to promote meaningful learning (Mayer \& Moreno, 2003).

Should the lesson content be given auditorily in a form of audio material, visually in a form of text slides, or a combination of both? Should the visual and auditory materials be presented simultaneously, sequentially, or separately? Should a teacher design a lesson presentation in full motion or video format? Which one is effective? What is the best combination? What verbal and visual cues should be included to make multimedia materials totally effective? What is the most systematic and iterative process for designing instruction or training used to improve students' performance? These are only few of the many questions that bother educators in their attempt to design and deliver effective instruction.

To help answer these questions was the primary motivation of the researcher to conduct this study. It is his aim to help understand how multimedia instructional materials can be used in ways (combination of cues) that are consistent with how students learn.

To this effect, the researcher derived ideas from 12 principles of instructional design by Mayer (2009), such as the following:

1. Coherence Principle: People learn better when extraneous material is excluded rather than included;

2. Signaling Principle: People learn better when cues that highlight the organization of the essential material are added;

3. Redundancy Principle: People learn better from graphics and narration than from graphics, narration, and printed text;

4. Spatial Contiguity Principle: People learn better when corresponding words and pictures are placed near each other rather than far from each other on the page or screen;

5. Temporal Contiguity Principle: People learn better when corresponding words and pictures are presented at the same time rather than in succession;

6. Segmenting Principle: People learn better when a multimedia lesson is presented in user-paced segments rather than as a continuous unit;

7. Pre-training Principle: People learn more deeply from a multimedia message when they receive pre-training in the names and characteristics of key components;

8. Modality Principle: People learn better from graphics and narration than from graphics and printed text;

9. Multimedia Principle: People learn better from words and pictures than from words alone.

10. Personalization Principle: People learn better from a multimedia presentation when the words are in conversational style rather than in formal style;

11. Voice Principle: People learn better when the words in a multimedia message are spoken by a friendly human voice rather than a machine voice;

12. Image Principle: People do not necessarily learn more deeply from a multimedia presentation when the speaker's image is on the screen rather than not on the screen.

Anchoring to the above-stated theories and/or principles of multimedia materials design, this study varied the degree of visual and verbal cues present in multimedia instruction to determine the effects on education students' vocabulary achievement. These variations include the following: (a) video-full visual and verbal 
cues; (b) still picture, text, and audio — limited visual and full verbal cues; (c) still picture and text—limited visual and no verbal cues; and (d) audio only - no visual and full verbal cues. The different visual and verbal cues being referred in this study are: facial expression, gesture, proximity, and appearance (visual cues) and voice inflections (verbal cues) of the lecturer in multimedia instruction.

The results of this study will assist educators in their decisions regarding how much amount of cues their multimedia instructional materials should have in order to most benefit the learner. It may also assist them in providing empirical evidence for justifying how multimedia technology can be used effectively in education.

Authorities clearly point out that "Educators and decision-makers at all levels need to see convincing evidence of the claimed instructional effectiveness of multimedia applications before they make the considerable investment in hardware, courseware, and teacher training that successful integration requires" (Yildiz \& Atkins, 1993).

Similarly, there is a great need for research on vocabulary learning strategies utilized by language learners of different proficiency levels and ages, its various pedagogical methods for vocabulary acquisition can help English as a second language students increase their vocabulary. But, the effectiveness of the various pedagogies for vocabulary acquisition using multimedia computer-assisted language learning (CALL) needs to be studied.

As such, the researcher intended to conduct this study in order to set direction towards a more effective teaching of vocabulary (and eventually of other learning contents) and designing and/or enriching multimedia materials appropriate for the purpose.

\section{Method}

This is an experimental research which used the randomized multi-group with a pre-test and post-test design. In this design, two or more experimental variables are tested. The groups are formed equal to the number of experimental variables. The members of each group are assigned randomly to their respective groups. Each experimental factor is applied on the group to which it is assigned. Before the experimental period, a pre-test is administered. After the experimental period, the same test as based from the lessons taken by all the groups is given to all of them. The results of the pre-test and those of the post-test are subjected to some statistical methods, generally the Analysis of Variance (ANOVA). The experimental factor assigned to the group with the highest achievement is considered the most effective, the experimental factor assigned to the group with the second highest achievement is the second most effective, and so on.

The basic structure of this design is as follows:

$\begin{array}{llll}\text { R } & \text { T1 } & \text { X1 } & \text { T2 } \\ \text { R } & \text { T1 } & \text { X2 } & \text { T2 } \\ \text { R } & \text { T1 } & \text { X3 } & \text { T2 } \\ \text { R } & \text { T1 } & \text { X4 } & \text { T2 }\end{array}$

where,

$\mathrm{R}=$ The subjects have been randomly assigned to different groups;

$\mathrm{T} 1=$ Pre-test;

$\mathrm{X}=$ Treatments;

$\mathrm{T} 2=$ Post-test.

This research varied the visual and verbal cues present in multimedia language instruction for four TGs. 
Four experimental variables were used: (a) video: full visual and verbal cues; (b) still picture, text, and audio: limited visual and full verbal cues; (c) still picture and text: limited visual and no verbal cues; and (d) audio only: no visual and full verbal cues. This aimed to determine the effects of these differently cued multimedia language instruction on the vocabulary achievement of education students. Figure 1 shows the schematic diagram of the study:

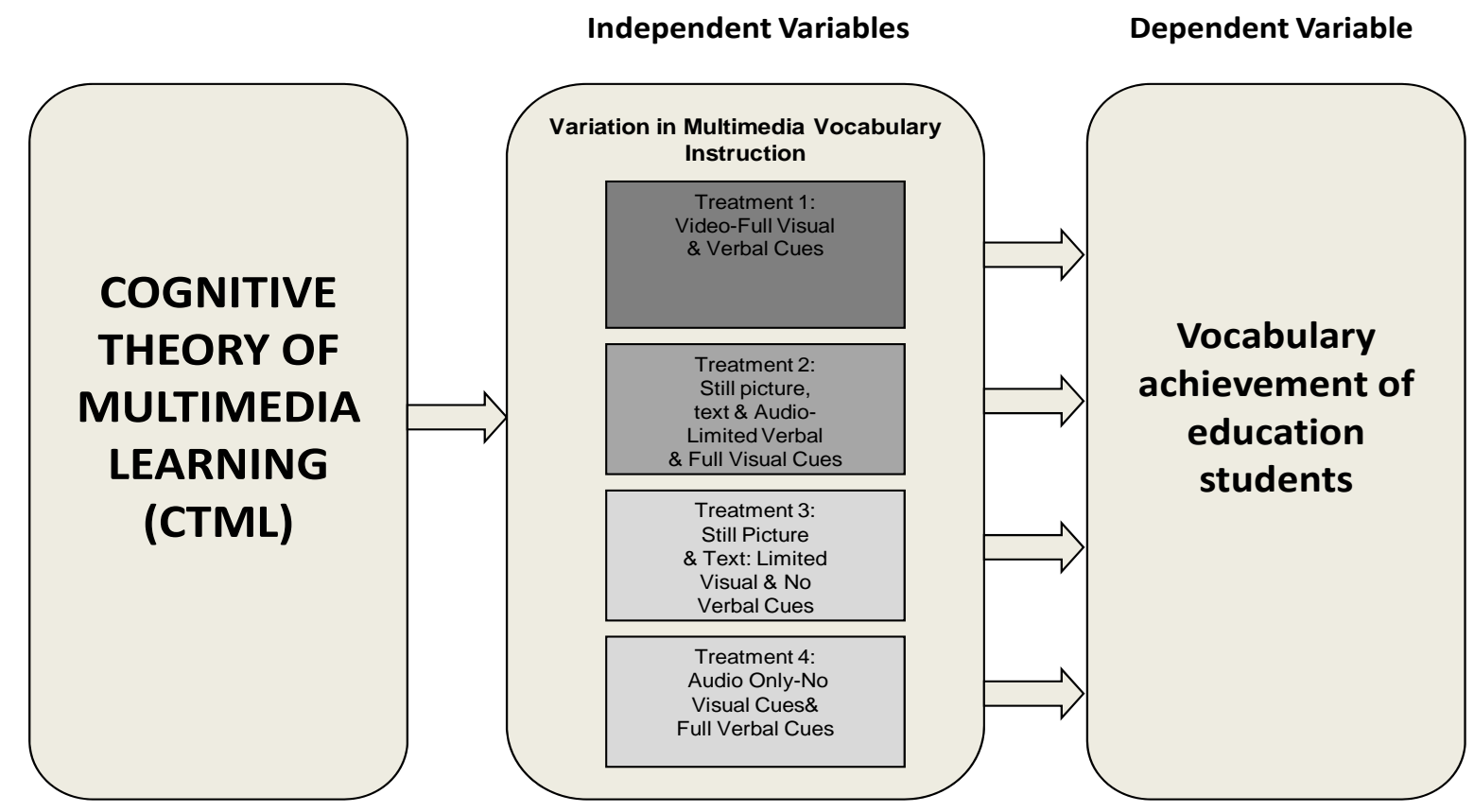

Figure 1. The schematic diagram of the study.

\section{Research Participants}

The TGs were composed of first-year Bachelor of Secondary Education (BSEd I) students of English II: Writing in the Discipline during the second semester of the academic year 2012-2013. They were equated according to group size, mental ability, and vocabulary ability.

Mental ability was based on the results of the Mental Ability Test (MD5 Mental Ability Test), which is one of the components of the entrance examination.

The respondents were grouped using randomized matching. Randomized matching means matching subjects first and then randomly assigning to groups. Hence, from the result of the MD5 Mental Ability Test, the researcher segregated the names of students who have the above-average mental ability. Considering that this study needed four TGs, he then drew four names and randomly assigned each one to each of the four TGs. The same process was repeated for students who have average and/or low mental ability until the desired number of respondents per group was completed and equated.

As to vocabulary ability, the scores obtained by the students in the Gate-MacGinitie Reading Test (Vocabulary Test only) were treated as raw scores and became the basis of equating the four groups in vocabulary ability.

Table 1 presents the distribution of the research participants in four TGs and Table 2 shows the scores of the participants in both mental ability and vocabulary ability tests. 
Table 1

Distribution of the Research Subjects in TGs

\begin{tabular}{lc}
\hline TG & $N$ \\
\hline $\mathrm{TG}_{1}$ : Multimedia language instruction with full visual and verbal cues & 15 \\
$\mathrm{TG}_{2}$ : Multimedia language instruction with limited visual and full verbal cues & 15 \\
$\mathrm{TG}_{3}$ : Multimedia language instruction with limited visual and no verbal cues & 15 \\
$\mathrm{TG}_{4}$ : Multimedia language instruction with no visual and full verbal cues & 15 \\
Total: & 60 \\
\hline
\end{tabular}

Table 2

Mental Ability and Vocabulary Ability Scores of the Research Participants

\begin{tabular}{|c|c|c|c|c|c|c|c|c|}
\hline \multirow{2}{*}{ Subjects } & \multicolumn{2}{|c|}{$\mathrm{TG}_{1}$} & \multicolumn{2}{|c|}{$\mathrm{TG}_{2}$} & \multicolumn{2}{|c|}{$\mathrm{TG}_{3}$} & \multicolumn{2}{|c|}{$\mathrm{TG}_{4}$} \\
\hline & MA & VA & MA & VA & MA & VA & MA & VA \\
\hline 1 & 96 & 39 & 96 & 34 & 96 & 45 & 96 & 39 \\
\hline 2 & 91 & 37 & 91 & 34 & 91 & 40 & 91 & 33 \\
\hline 3 & 88 & 38 & 88 & 35 & 88 & 41 & 88 & 39 \\
\hline 4 & 83 & 36 & 83 & 34 & 83 & 39 & 83 & 34 \\
\hline 5 & 78 & 38 & 75 & 34 & 78 & 34 & 75 & 33 \\
\hline 6 & 65 & 34 & 70 & 36 & 65 & 24 & 70 & 30 \\
\hline 7 & 61 & 31 & 61 & 31 & 61 & 36 & 61 & 39 \\
\hline 8 & 57 & 32 & 57 & 36 & 57 & 23 & 57 & 33 \\
\hline 9 & 52 & 27 & 52 & 29 & 52 & 24 & 52 & 34 \\
\hline 10 & 50 & 36 & 50 & 34 & 50 & 35 & 50 & 35 \\
\hline 11 & 45 & 36 & 45 & 33 & 45 & 36 & 45 & 28 \\
\hline 12 & 36 & 40 & 36 & 34 & 36 & 34 & 36 & 35 \\
\hline 13 & 33 & 23 & 33 & 29 & 33 & 36 & 33 & 28 \\
\hline 14 & 27 & 35 & 27 & 30 & 27 & 33 & 27 & 35 \\
\hline 15 & 17 & 34 & 17 & 36 & 17 & 30 & 17 & 36 \\
\hline Total & 58.6 & 34.4 & 58.73333 & 33.26667 & 58.6 & 34 & 58.73333 & 34.06667 \\
\hline
\end{tabular}

Notes. MA = Mental ability; and VA = Vocabulary ability.

\section{Instruments}

Gates-MacGinitie Reading Test. For the purpose of equating the subjects of this study in terms of their vocabulary skills, the researcher administered the Gates-MacGinitie Reading Test (Vocabulary Test only). This reading test was constructed by Arthur Gates and Walter MacGinitie. However, the norms in terms of grades and standard scores established by Gates and Mac Ginitie were modified to suit Filipino students.

Multimedia language instructional materials. The study consisted of four treatments designed to vary the number of visual and verbal cues within the multimedia language instruction. The review of literature indicated that visual and verbal cues, such as facial expressions, gestures, proximity, appearance, vocal inflection, humor, personalized examples, and raising questions might affect a student's perception of the social presence of a speaker which eventually affects their learning (Steffey, 2001). The treatments vary in the degree to which they shall convey facial expressions, gestures, proximity, appearance, and vocal inflections.

Along with the materials' vocabulary contents, several recommendations by Steffey were considered in choosing these materials:

1. The materials must not be too long, because fatigue may be an intervening variable;

2. Instructional lessons must not contain racist, sexist, and heterosexist language in order not to offend any 
participants which shall eventually lose their interest to the lessons;

3. The materials must bring into play dynamic instructors or hosts in order to convey higher social presence and motivation on the part of the learners.

Vocabulary achievement test (pre-test and post-test). The research used a researcher-made 50-item multiple-choice test properly represented by the six multimedia lessons on vocabulary. The test was validated by five experts. The reliability of this test was established using the Kuder-Richardson (K-R 21) formula. It has a reliability coefficient of 0.791 .

Modified Hollingshead Four-Factor Index of Social Status. The four-factor index of socio-economic status (SES) was utilized to measure SES of the research participants. This scale, widely used in the social sciences, uses parents' education, occupation, and income to measure SES.

Multimedia Technology Acceptance/Attitude Questionnaire. This survey instrument was adapted from the questionnaire used by Henderson (2005) in her study "The Role of Computer Access in E-learning Technology Acceptance by Business Students", modified to suit the purpose of this study which is to survey on the education students' acceptance/attitudes towards the use of multimedia technology.

This research instrument, as adapted and modified, came up to have 14-item scales. A Likert-scale was used to elicit participants' responses on a scale from 1 to 5 ( 1 = "Strongly negative"; 2 = "Negative"; 3 = "Neutral"; 4 = "Positive"; and 5 = "Strongly positive").

\section{Procedures for Data Gathering}

\section{Pre-experiment}

Choosing and equating the research participants. For the purpose of conducting the experiment, the subjects were randomly chosen from the list of officially enrolled first-year BSEd I students. They were equated according to group size, mental ability, and vocabulary ability. In anticipation of this research study, the grouping and/or sectioning was already done before the start of classes in the second semester of the academic year 2012-2013.

Validity and reliability of the test instrument. To assure validity and reliability of the instrument, the researcher did the following procedures.

Planning the test. The researcher carefully observed the procedures in test planning which included the preparation of the table of test specification.

Constructing the test items. The researcher constructed a total of 63 -item multiple-choice test for the six lessons. The items were intentionally made more than the needed number of items (50) in anticipation of item elimination after test item analysis. The test was based from the transcripts of the materials used in the study and focused on vocabulary in context, idiomatic expressions, and slang.

The researcher used multiple-choice type of test which is considered the most flexible and the most effective test type for measuring information, vocabulary, understanding, application of principles, or ability to interpret data.

Validating the test. The 63-item test was validated by experts. The panel of validators concertedly rated the test "valid".

Trial administration. After the validation process, the test was administered to 32 students who were non-participants in this study. Results of the pilot testing were utilized for analysis of the test items.

Analyzing the test items. After the trial testing, the test papers were corrected and analyzed. 
Administering pre-test. A pre-test (T1) containing the actual test items of the achievement test was administered to the participants. This was to determine how well the participants know the vocabulary contents before treatment.

\section{During Treatment}

Preparing the experiment venue (speech laboratory). In preparing the venue, the researcher tried not to overlook any other intervening factors that might affect the validity and reliability of the result of the study. The following were foreseen intervening factors and how each one was avoided:

1. Sitting arrangement: There was no pre-determined seat plan imposed. The participants were allowed to sit anywhere they wanted so that sitting inconvenience as an intervening factor was eliminated;

2. Lighting: The speech lab was well-lit during the conduct of experiments in order to eliminate bad lighting as an intervening factor;

3. Ventilation: The lab is equipped with $1.5 \mathrm{HP}$ air conditioning unit. During the treatment, this was set in a tolerable coolness so that poor ventilation was eliminated as a factor;

4. Noise and other outside interferences: The lab is a closed/secluded room, thus, any noises from the outside were surely avoided;

5. Sound quality: The multimedia instructional material for each TG was played though a computer at the teacher's control panel and was projected via LCD projector; in order for each participant to get an equal quality of sounds from the materials (except $\mathrm{TG}_{3}$ ), they used the headset available at their individual booth.

Conducting the actual experiment. The researcher completed the actual conduct of this experiment in four weeks. To protect this study from the Hawthorne Effect - the effect which refers to the tendency of subjects to act differently when they know they are being studied, the experiments were made part of the regular classroom meetings for the subject English II, usually during the last 20 minutes of the class period. A five-minute break was observed in between conducts of the regular subject matter session and the experimental lesson of the day.

The participants for each TG were not informed that they were experimented. The teacher-researcher devised merit and demerit system to help treat absences most especially by the participants. At an instance that a participant made a valid absence during the conduct of the experiment, the researcher discretely and immediately subjected him/her to special exposure to the treatment material missed.

The following are the descriptions of the four treatments:

1. Treatment $1\left(\mathrm{TG}_{1}\right)$ : The language instruction was in a full-motion video. The host is in a half-body shot presenting the lesson contents, moving occasionally from left to right or vice versa. Text information, consisted of an outline of key points of the lecture, was flashing simultaneously as presented/uttered by the host and the guest-interviewee. The text information appeared at the right, left, or bottom part of the screen. All visual and verbal cues were used in this treatment: facial expressions, gestures, proximity, appearance, text, and vocal inflection.

The materials were played using iTune player.

2. Treatment $2\left(\mathrm{TG}_{2}\right)$ : The language instruction consisted of slide show of "still images" of the host and the guest-interviewee and other pictorial elements of the materials, text information containing the key points of the lecture appear simultaneously with the audio. The presentation eliminated and/or limited the motion. A proper credit to the original source was observed in order not to violate the copyright agreement. 
This treatment included the visual and verbal cues of proximity, appearance, text, and vocal inflection. Facial expressions and gesture cues were eliminated in this treatment.

The materials were played using Windows Media Player.

3. Treatment $3\left(\mathrm{TG}_{3}\right)$ : The language instruction consisted of a still image of the host and the guest-interviewee. The still images remained the same throughout the lesson. A transcript of the instructional text was placed at the right side of the screen beside the still image. The text information, consisted of an outline of key points of the lecture, changed on cue as the instructional text screen changed. Audio was eliminated in this treatment. Proper credit to the original source was observed in order not to violate the copyright agreement.

This treatment included the visual cues of appearance, proximity, and text. Facial expressions, gestures, and vocal inflection cues were eliminated in this treatment.

The materials were presented using Microsoft PowerPoint.

4. Treatment $4\left(\mathrm{TG}_{4}\right)$ : The instruction consisted of full audio of the original materials only. This treatment included the verbal cues of voice inflections only. Facial expressions, gestures, proximity, and appearance were eliminated from this treatment.

The audio materials were played using iTune player.

Table 3 presents the summary of visual and verbal cues used in each of the treatment materials.

Table 3

Visual and Verbal Cues Present in Four Treatment Materials

\begin{tabular}{lllllll}
\hline Treatment & \multicolumn{5}{c}{ Visual } & Verbal \\
\cline { 2 - 6 } & Facial expressions & Gestures & Proximity & Appearance & Text & Vocal inflection \\
\hline Treatment 1 & $*$ & $*$ & $*$ & $*$ & $*$ & $*$ \\
Treatment 2 & & $*$ & $*$ & $*$ & $*$ \\
Treatment 3 & & $*$ & $*$ & & $*$ \\
Treatment 4 & & & & & $*$ \\
\hline
\end{tabular}

\section{Treatment of Data}

The study consisted of four TGs with 15 participants in each group. Treatment 1 provided the greatest number of visual and verbal cues. Each subsequent TG used fewer cues.

A one-way ANOVA was used to determine if there are significance differences in means and whether the differences among mean scores are statistically significant among TGs. ANOVA allows various mean variables to be measured, allows two or more independent variables to be analyzed simultaneously, and also allows for the measurement of the interactional effects.

Pearson $r$ was used to determine if vocabulary achievement is significantly related to respondents' age, socio-economic index, GPA in English I, and attitudes towards multimedia materials, while Chi-square was used to find out if vocabulary achievement is significantly related to respondents' gender and secondary school type graduated.

Data were computed using a Window-based Statistical Package for the Social Sciences (SPSS) with the help of a qualified statistician.

\section{Scoring Procedures}

Achievement test. Correct answers for each of the 50 items received scores of " 1 " and incorrect answers 
received scores of "0".

The total 50 items were summed up to create an achievement score for each participant. The scale of mean score and verbal interpretation for vocabulary achievement test were interpreted in Table 4.

Table 4

Scale of Mean Score and Verbal Interpretation for Vocabulary Achievement Test

\begin{tabular}{ll}
\hline Mean & Verbal interpretation \\
\hline $41-50$ & Very high \\
$31-40$ & High \\
$21-30$ & Average \\
$11-20$ & Low \\
$1-10$ & Very low \\
\hline
\end{tabular}

Multimedia technology acceptance/attitude. The respondents' scores to each of the 14-item scale were totaled and divided by 14 . For each TG, the mean was summed up and divided by 15 research subjects. The scale of mean score and verbal interpretation for multimedia technology acceptance/attitude were interpreted in Table 5.

Table 5

Scale of Mean Score and Verbal Interpretation for Multimedia Technology Acceptance/Attitude

\begin{tabular}{ll}
\hline Mean & Verbal interpretation \\
\hline $4.21-5.00$ & Strongly positive \\
$3.41-4.20$ & Positive \\
$2.61-3.40$ & Neutral \\
$1.61-2.60$ & Negative \\
$1.00-1.60$ & Strongly negative \\
\hline
\end{tabular}

GPA in English I. Based on the standards of the NONESCOST, the scale GPA in English I and verbal interpretation were interpreted in Table 6 .

Table 6

Scale of GPA and Verbal Interpretation

\begin{tabular}{ll}
\hline Range & Verbal interpretation \\
\hline $95.00-99.99$ & Very high \\
$90.00-94.99$ & High \\
$85.00-89.99$ & Average \\
$80.00-84.99$ & Low \\
$75.00-79.99$ & Very low \\
\hline
\end{tabular}

\section{Results}

The vocabulary achievement of each TG before and after exposure to multimedia language instruction is high (see Tables 7 and 8).

The obtained mean scores of the four TGs were different after exposure to treatments and increase in their scores was noted in comparison to their scores before exposure. However, the interpretations of their vocabulary achievement were almost the same. Although the obtained mean scores by each TG before and after experiment were similarly interpreted "High", increase in scores was noted in the post-test. After the treatments, 
$\mathrm{TG}_{1}$ (video: full visual and verbal cues) obtained the highest mean (38.07); $\mathrm{TG}_{2}$ (still picture, text, and audio: limited visual and full verbal cues) obtained the second highest mean (37.40); $\mathrm{TG}_{3}$ (still picture and text: limited visual and no verbal cues) ranked third (36.80); and $\mathrm{TG}_{4}$ (audio only: no visual and full verbal cues) ranked fourth (34.53).

Table 7

Vocabulary Achievement of Each TG Before Exposure to Respective Multimedia Language Instruction

\begin{tabular}{lllll}
\hline $\mathrm{TG}$ & $N$ & $M$ & $S D$ & Interpretation \\
\hline $\mathrm{TG}_{1}$ & 15 & 31.47 & 6.43 & High \\
$\mathrm{TG}_{2}$ & 15 & 31.27 & 4.22 & High \\
$\mathrm{TG}_{3}$ & 15 & 32.13 & 6.55 & High \\
$\mathrm{TG}_{4}$ & 15 & 31.27 & 5.56 & High \\
\hline
\end{tabular}

Table 8

Vocabulary Achievement of Each TG After Exposure to Multimedia Language Instruction

\begin{tabular}{lllll}
\hline $\mathrm{TG}$ & $N$ & $M$ & $S D$ & Interpretation \\
\hline $\mathrm{TG}_{1}$ & 15 & 38.07 & 6.15 & High \\
$\mathrm{TG}_{2}$ & 15 & 37.40 & 2.69 & High \\
$\mathrm{TG}_{3}$ & 15 & 36.80 & 5.62 & High \\
$\mathrm{TG}_{4}$ & 15 & 34.53 & 5.80 & High \\
\hline
\end{tabular}

Further analysis of the data disclosed that $\mathrm{TG}_{1}$ obtained the highest mean of 38.07 among the treated groups, which means that the treatment in this group (video or multimedia language instruction with full visual and verbal cues) was the most helpful among other groups' materials considering that they were almost equal before the different treatments. This result is supported by Ciccone (1995) who derived conclusion from his study that "Authentic video materials stimulate language acquisition and are thus an excellent source of comprehensible input".

The findings about the two multimedia materials, such as video (full visual and verbal cues) and still picture with audio (limited visual and full verbal cues), being identified as the first and second most effective materials, support the findings of Steffey (2001) when she conducted a study of the same nature to 150 students who were randomly assigned to five TGs. The TGs received three computer-based multimedia lessons on "inclusive and exclusive language" that included full visual and verbal cues (video) as Treatment 1, limited visual and full verbal cues (still picture with audio) as Treatment 2, limited visual cues and no verbal cues (still picture and text) as Treatment 3, no visual cues and full verbal cues (audio only) as Treatment 4, or no visual or verbal cues (text only) as Treatment 5 . In terms of achievement, her study revealed that Treatment 1 (video) earned the highest mean of 23.07, followed by Treatment 2 (still picture with audio) with 22.87 as the second highest.

Unlike the recent study, however, Treatment 4 (audio only) ranked third with 22.70, Treatment 5 (text only) ranked fourth with 21.93, and Treatment 3 (still picture and text) ranked last with 21.53. This study and the recent study imply that it is not safe to say that materials in audio only are less effective.

Furthermore, some of the findings in this recent study support the findings of Lee and Bowers (1997), who studied a group of university students to determine under which set of conditions people learned best. The participants were given a pre-test, they then learned the material, and then were given a post-test. Their learning was compared with the learning of a control group that took the same pre-test and post-test, but studied a 
different topic in-between. When compared with the learning performance of the control group, the people in the different groups always demonstrated more learning, such as (a) hearing spoken text and looking at graphics $-91 \%$ more learning; (b) looking at graphics alone $-63 \%$ more; (c) reading printed text plus looking at graphics $-56 \%$ more; (d) listening to spoken text, reading text, and looking at graphics $-46 \%$ more; (e) hearing spoken text plus reading printed text $-32 \%$ more; (f) reading printed text alone $-12 \%$ more; and (g) hearing spoken text alone $-7 \%$ more. This study and the recent study have the common finding that material in audio only is less effective and/or demonstrated lesser amount of learning.

Results of ANOVA showed no significant difference on the vocabulary achievement among the four TGs before and after exposure to multimedia language instruction (see Tables 9 and 10).

Table 9

Significant Difference on the Vocabulary Achievement of the Four TGs Before Exposure to Multimedia Language Instruction

\begin{tabular}{lcccccc}
\hline Sources of variation & Sum of squares & $D f$ & Mean squares & F-ratio & F-prob. & Interpretation \\
\hline Between groups & 7.60 & 3 & 2.53 & & & Not significant \\
Within groups & 1861.33 & 56 & 33.24 & 0.08 & 0.973 & \\
Total & 1866.93 & 59 & & & & \\
\hline
\end{tabular}

Note. Significant at $p \leq 0.05$ level.

Table 10

Significant Difference on the Vocabulary Achievement of the Four TGs After Exposure to Multimedia Language Instruction

\begin{tabular}{lcrllll}
\hline Sources of variation & Sum of squares & $D f$ & Mean squares & F-ratio & $F$-prob. & Interpretation \\
\hline Between groups & 105.93 & 3 & 35.31 & & & Not significant \\
Within groups & 1544.67 & 56 & 27.58 & 1.28 & 0.290 & \\
Total & 1650.60 & 59 & & & & \\
\hline
\end{tabular}

Note. Significant at $p \leq 0.05$ level.

No significant relationship was found between gender and vocabulary achievement, secondary school type and vocabulary achievement, socio-economic index and vocabulary achievement, and attitudes and vocabulary achievement. However, significant relationships were noted between age and vocabulary achievement and GPA in English I and vocabulary achievement (see Table 11).

Table 11

Significant Relationship Between Vocabulary Achievement and the Identified Variables in the Profile of the Nursing Students

\begin{tabular}{lllll}
\hline Variables correlated & $N$ & Correlation $(r)$ value & $p$-value & Interpretation \\
\hline Age and vocabulary achievement & 60 & -0.375 & 0.003 & Significant \\
Socio-economic index and vocabulary achievement & 60 & -0.080 & 0.546 & Not significant \\
GPA in English and vocabulary achievement & 60 & 0.255 & 0.049 & Significant \\
Attitudes and vocabulary achievement & 60 & 0.238 & 0.068 & Not significant \\
\hline Gender and vocabulary achievement & & & $X^{2}$-value & Not significant \\
Secondary school type and vocabulary achievement & 60 & 0.060 & 0.718 & Not significant \\
\hline
\end{tabular}

GPA in English I is significantly related to vocabulary achievement. The finding of significant relationship 
between GPA and vocabulary achievement supports the findings of Mustafa (2001), who conducted a study to investigate the factors involved in applying multimedia in teaching English as a foreign language. In particular, it dealt with the non-courseware factors affecting the use of multimedia in improving the pronunciation and oral communications skills of students majoring in English for specific purposes at the Jordan University for Science and Technology. The factors under investigation were the following: previous instruction in pronunciation using the conventional classroom teaching method, familiarity with multimedia, English proficiency, academic achievement, free time using multimedia, attitudes towards using multimedia, and socio-economic class. This study showed that using computers, especially multimedia, as a teaching aid in developing the oral skills of English majors is influenced by several non-courseware and one of them was the general GPA of the respondents.

\section{Conclusion}

In general, it can be gleaned from the results of the present study that the higher number of visual and verbal cues present in a multimedia instructional material can also create correspondingly higher effects on the achievement (test scores) of the learners. Although, the four TGs did not differ significantly in their vocabulary achievement, but their obtained mean can prove that the more cues present in a multimedia material, the better learning/scores it can generate. Hence, a video or multimedia material with full visual and verbal cues is a lot better than a material in audio only or no visual and full verbal cues.

The finding of no significant difference among the four variedly-cued treatment materials in terms of learners' achievement implies that the teachers and instructional designers have the leeway to choose and design materials according to their skills, time, and resources, and most importantly, to the needs of the students and learning environment. They may find the results of this study interesting for a simple reason that they need not be overly concerned about placing themselves in complicated situations when preparing multimedia or computer-based instruction. For a time-constrained instruction, a very time-consuming process of creating full-motion video (i.e., videotaping the instructor, setting up lights, microphones, etc.) may not be warranted because easy-to-prepare materials (materials with lesser amount of cues to consider) can most likely deliver the same effect to learning.

\section{References}

Betrancourt, M. (2007). Sequential display of multimedia instructions: Effect on users' understanding. Retrieved December 30, 2013, from http://csdl2.computer.org/

Ciccone, A. (1995). Teaching with authentic video: Theory and practice. In F. R. Eckman, D. Highland, P. W. Lee, J. Mileham, \& R. R. Weber (Eds.), Second language acquisition theory and pedagogy. Mahwah, N.J.: Lawrence Erlbaum Associates.

Davidson, J. (n.d.). Multimedia presentation. In B. Hoffman (Ed.), Encyclopedia of educational technology. Retrieved December 30, 2013, from http://coe.sdsu.edu/eet

Foster, M. (2005). Multimedia design controversies. In B. Hoffman (Ed.), Encyclopedia of educational technology. Retrieved December 30, 2013, from http://coe.sdsu.edu/eet

Garcia, J. (2001). An instrument to help teachers assess learners' attitudes towards multimedia instruction. Retrieved December 30, 2013, from http://findarticles.com

Hede, T., \& Victoria, A. H. (2002). Multimedia effects on learning: Design implications of an integrated model. Australian Society for Educational Technology. Retrieved December 30, 2013, from http://www.aset.org.au/confs/2002/hede-t.html

Henderson, R. (2005). The role of computer and internet access in business students' acceptance of e-learning technology. Virginia Polytechnic Institute and State University: Digital Library and Archives. Retrieved December 30, 2013, from http://scholar.lib.vt.edu/theses\&dissertation/ 
Houghton, R. S. (2004). Rationale for multimedia use and instruction in education. Retrieved December 30, 2013, from http://www.ceap.wcu.edu/Houghton/MM/Rationale

Iheanacho, C. C. (n.d.). Effects of two multimedia computer-assisted language learning programs on vocabulary acquisition of intermediate level ESL students. Virginia Polytechnic Institute and State University: Digital Library and Archives. Retrieved December 30, 2013, from http://scholar.lib.vt.edu/theses\&dissertation/

Lee, A. Y., \& Bowers, A. N. (1997). Best combinations. In B. Bailey (Ed.), Multimedia and learning. Retrieved December 30 , 2013, from http://www.humanfactors.com

Mayer, R. E. (2009). Multimedia learning (2nd ed.). New York, N.Y.: Cambridge University Press.

Mayer, R. E. (2003). The promise of multimedia learning: Using the same instructional design methods across different media. Learning and Instruction, 13, 125-139.

Mayer, R. E. (2010). Cognitive theory of multimedia learning. Retrieved December 30, 2013, from http://sorden.com/portfolio/ sorden_draft_multimedia2012.pdf

Mayer, R. E., \& Moreno, R. (2003). Nine ways to reduce cognitive load in multimedia learning. Educational Psychologist, 38(1), 43-52.

McLaren, B. M., DeLeeuw, K. E., \& Mayer, R. E. (2011). Polite Web-based intelligent tutors: Can they improve learning in classrooms? Computers \& Education, 56, 574-584.

Mustafa, Z. (2001). Non-courseware factors involved in using multimedia in foreign language instruction. Retrieved December 30 , 2013, from http://www.eric.ed.gov/ERICWebPortal/Home.portal

Schnotz, W. (2008). Why multimedia learning is not always helpful. In J. F. Rouet, R. Lowe, \& W. Schnotz (Eds.), Understanding multimedia documents (pp. 17-41). New York, N.Y.: Springer.

Shank, P. (2005). The value of multimedia in learning. Retrieved December 30, 2013, from http://www.learningpeaks.com

Sorden, S. D. (2012). The cognitive theory of multimedia learning. Retrieved December 30, 2013, from http://sorden.com/portfo lio/sorden_draft_multimedia2012.pdf

Steffey, C. S. (2001). The effects of visual and verbal cues in multimedia instruction. Virginia Polytechnic Institute and State University: Digital Library and Archives. Retrieved December 30, 2013, from http://scholar.lib.vt.edu/theses\&dissertation/

Technology Management Center/University of the Philippines. (2008). Technology management. Retrieved December 30, 2013, from http://www.tmc.upd.edu.ph/

Walden, S. (2005). What is educational technology. In B. Hoffman (Ed.), Encyclopedia of educational technology. Retrieved December 30, 2013, from http://coe.sdsu.edu/eet

Yildiz, R., \& Atkins, M. (1993). Evaluating multimedia applications. Computers and Education, 21(1/2), 133-139. 